\title{
KRAS Codon 12 and 13 Mutations in Gastric Cancer in the Northeast Iran
}

\author{
Hossein Ayatollahi', AlirezaTavassoli ${ }^{2}$, Amir Hossein Jafarian ${ }^{3}$, Amin Alavi ${ }^{4}$, Sepideh Shakeri ${ }^{5}$, Seyyede Fatemeh \\ Shams ${ }^{5}$, Maryam Sheikhi ${ }^{5}$, Neda Motamedi Rad ${ }^{5}$, Mohammad Hadi Sadeghian ${ }^{1 *}$, Afsane Bahrami ${ }^{6}$
}

1.Cancer Molecular Pathology Research Center, Mashhad University of Medical Sciences, Mashhad, Iran

2. Endoscopic and Minimally Invasive Surgery Research Center, Mashhad University of Medical Sciences, Mashhad, Iran

3. Dept. of Pathology, Cancer Molecular Pathology Research Center, Mashhad University of Medical Sciences, Mashhad, Iran

4. Faculty of Medicine, Mashhad University of Medical Sciences, Mashhad, Iran

5. Cancer Molecular Pathology Research Center, Ghaem Hospital, Mashhad University of Medical Sciences, Mashhad, Iran

6. Dept. of Modern Sciences and Technologies, School of Medicine, Mashhad University of Medical Sciences, Mashhad, Iran

\begin{tabular}{c}
\hline KEYWORDS \\
\hline K-ras; \\
Mutations \\
Gastric Cancer \\
\end{tabular}

\section{Article Info}

Received 13 Dec 2016; Accepted 08 Aug 2017;

Published Online 17 July 2018;

\section{ABSTRACT}

Background \& objective: KRAS mutations are reported in many types of cancers including pancreas, lung, colon, breast,and gastric (GC). High frequency of $K R A S$ mutation is observed in the pancreas,colon, and lung cancers; they commonly arise in codon 12 and 13 of exon 2. Due to the lack of information about the frequency of $K R A S$ mutations in the Northeast of Iran, the currentstudy aimed at evaluating $K R A S$ frequency in cases with $\mathrm{GC}$ in this region.

Methods: A total of 120 formalin-fixed, paraffin-embedded blocks of patients with GC were assessed. The assays to detect KRAS in codon 12 and13 were obtained through the peptide nucleic acid (PNA)-clamp.

Results: Totally 87 male and 33 female patients were analyzed in the current study. The mean age of the subjects was 55years. The most common tumoral fragment was located on the body with 48 cases $(40 \%)$ and the less frequent was related to fondues with six cases (5\%). Of the $120 \mathrm{GC}$ samples, 16(13.3\%) caseshad codon $12 \mathrm{KRAS}$ mutation, and $16.7 \%$ had codon 13 mutations. There were no significant relationships between gender,age, and KRAS mutations in the studied specimens.

Conclusion: In conclusion, the overall frequency of KRAS codon 12 and 13 mutations in GC was 30\% in the current study population.Frequency of $K R A S$ codon 12 and 13 mutations hadsignificant correlation with tumors location. Different pathogenic mechanismsare suggested for GC according to tumor location. The current study resultsmay be an important diagnostic tool for physicians managing atrophic gastritis.

Mohammad Hadi Sadeghian, Cancer Molecular Pathology Research Center, Mashhad Corresponding information: University of Medical Sciences, Mashhad, Iran E-mail: sadeghianmh@mums.ac.ir

Copyright (C) 2018, IRANIAN JOURNAL OF PATHOLOGY. This is an open-access article distributed under the terms of the Creative Commons Attribution-noncommercial 4.0 International License which permits copy and redistribute the material just in noncommercial usages, provided the original work is properly cited.

\section{Introduction}

Cancer is a global health challenge with high mortality; it is reported as the cause of 7.6 million deaths in 2008 (1). Gastric cancer (GC) is known as the feature common cancer worldwide, and has the second rate of mortality among cancers (2). Many patients with GC present with advanced disease and undergo treatment with preparative cytotoxic combination chemotherapy and surgery; they follow chemotherapy in the east and surgery in the west (1-3). In Iran, Northern and Northwestern regions are high risk areas for $\mathrm{GC}$, but there are several low and intermediate risk regions in other geographical areas (4). Pathogenesis of gastric adenocarcinomas shows a classic example of gene-environment interaction; therefore, geographical differences of the frequency of gastric adenocarcinomas may be due to genetic factors (5). GC is a heterogeneous disease, which progresses via different 
pathways of carcinogenesis; however, causes of this genetic heterogeneity are not studied thoroughly (6).

The study by Seung-Hyun (1986) was the first report on KRAS mutations in patients with GC; since then many studies investigated KRAS mutations status in the same field. More than $80 \%$ of studies were conducted on Asian patents with GC. The largest Western study included 82 patients with GC whereas the largest Asian study from Korea included 319 cases $(1,2)$.

GCs are classified according to tumor side and pathological characteristics of lesions. Laurens classification describes GC in four levels including differentiated, diffuse-type, infiltrated, and intestinaltype carcinomas, characterized by cohesive cells (5). K-RAS, a small G-protein belongs to RAS family and epidermal growth factor receptor $(E G F R)$ downstream, is a necessary component of EGFR signaling cascade (6). Unusual activation of EGFR-RAS-RAFMAP kinase pathway is observed in GC; in this cascade, activating mutations of EGFR gene induces ligand-independent activation of receptor, which leads to over activation of KRAS. Its downstream effectors play a significant role in EGFR-RAS-RAF-MAP kinas pathway. KRAS mutations alter gene conformation and induce KRAS protein activation. In general, KRAS mutations are contradictory to EGFR mutations; they can activate EGFR-RAS-RAF-MAP kinase cascades independent of EGFR mutation. Therefore, KRAS proteins appear to be resistant to EGFR inhibitors. KRAS mutations are known as a negative predictor, it is contended whether EGFR inhibitors are useful for GC, because $K R A S$ mutation status depends on $E G F R$ mutation status (7).

KRAS mutations are reported in many types of cancers including pancreas, lung, colon, breast, and GCs $(6,7)$. High frequency of KRAS mutation was observed in pancreas, colon, and lung cancers; they commonly arise in codons 12 and 13 of exon 2 (7). It was observed that DNA changes can distinguish tumor subtypes among histologically identified tumors (8). Peptide nucleic acid (PNA) is a synthetic nucleic acid, which binds to its complementary RNA or DNA sequences; PNAs have higher sensitivity, speed, sim- plicity, and lower cost(3). Due to lack of information about the frequency of KRAS mutations in the Northeast Iran, the current study aimed at evaluating it in GC cases.

\section{Material and Method}

The current cross sectional study was conducted in Ghaem Medical Center affiliated to Mashhad University of Medical Sciences, Mashhad, Iran in 2015 on 120 formalin-fixed, paraffin- embedded blocks of patients with GC. Hematoxylin and eosin (H\&E)stained sections of each tissue sample were examined by two expert pathologists to confirm histology. The selected blocks contained highest density of primary adenocarcinoma. The selected area contained more than $30 \%$ tumor cells in tissue and was marked on the slide to facilitate macro dissection. Up to 5-10$\mu \mathrm{m}$ sections were cut and the marked areas of interest were dissected using a sterile scalpel blade. Genomic DNA was extracted according to QIAMP DNA micro kit protocol (Qiagen, Hilden, Germany).

The KRAS mutations in codon 12 and 13 were assessed by the PNA-clamp (PANAGENE, Inc., Daejeon, Korea). PNA primers and probes were associated with the commercial kit. All reactions were done in $20 \mu \mathrm{L}$ volumes and SYBR Green was used; DNA was also used as template. The primers and PNA probes were set. PCR cycling conditions were as follows: five minutes hold at $94^{\circ} \mathrm{C}$ followed by 40 cycles of $94^{\circ} \mathrm{C}$ for 30 seconds, $63^{\circ} \mathrm{C}$ for 30 seconds and $72^{\circ} \mathrm{C}$ for 30 seconds. In this assay DNA primer and PNA probes were used together in the clamping reaction. The PNA probe sequence is complementary to wildtype DNA, suppresses amplification of wild-type targets; it enhances preferential amplification of mutant sequences by inhibiting DNA primers competitively. They bind to wild-type DNA, and positive signals are detected by intercalation of SYBR Green fluorescent dye. Efficiency of performed PCR was determined by measuring threshold cycle (CT) value. The delta CT (delta CT) value was calculated according to the following formula

$$
\text { [standard CT }]-[\text { sample } \mathrm{CT}]=\operatorname{delta} \mathrm{CT}
$$

The sample and standard CT values were from the 
tested and clamping control samples. The cut off delta CT was 2 for KRAS mutations.

\section{Statistical analysis}

SPSS version 16 was employed for statistical analysis. Chi-square and Fisher exact tests were applied. $\mathrm{P}$ value $<0.05$ was considered significant.

\section{Results}

The current study evaluated 120 patients with GC in order to identify KRAS mutations (codons 12 and 13); 87 patients were male and the rest of them female.
Mean age of the patients was 55 years. The most common tumoral location was related to body with 48 cases (40\%) and the less frequent was related to fondues with six cases (5\%). Of the $120 \mathrm{GC}$ samples, $16(13.3 \%)$ patients had codon 12 KRAS gene mutation and $16.7 \%$ had codon 13 mutation. There were no significant relationships between gender, age, and KRAS mutations.

The relationship of KRAS mutations with other clinical, pathological, and molecular parameters are summarized in Table 1.

Table 1 . Relationship of KRAS Mutations With Clinical, Pathological, and Molecular Parameters of Gastric Adenocarcinoma Cases

\begin{tabular}{|c|c|c|c|c|c|c|}
\hline & $\begin{array}{c}\text { Frequency of } \\
\text { KRAS Codon } \\
12 \text { Mutation }\end{array}$ & $\begin{array}{c}\text { Percentage of } \\
\text { KRAS Codon } \\
12 \text { Mutation }\end{array}$ & P-value & $\begin{array}{c}\text { Frequency of } \\
\text { KRAS Codon } \\
13 \text { Mutation }\end{array}$ & $\begin{array}{c}\text { Percentage of } \\
\text { KRAS Codon } \\
13 \text { Mutation }\end{array}$ & P-value \\
\hline \multicolumn{7}{|l|}{ Gender } \\
\hline Male & (87) 10 & 11.49 & 0.336 & (87) 14 & 16 & 0.784 \\
\hline Female & $(33) 6$ & 18 & & (33) 6 & 18 & \\
\hline \multicolumn{7}{|l|}{ Tumor Site } \\
\hline Cardia & (26) 4 & 15.38 & 0.250 & (26) 4 & 15.3 & 0.015 \\
\hline Fundus & (6) 2 & 33 & & (6) 4 & 66 & \\
\hline Body & (48) 8 & 16.6 & & (48) 8 & 16 & \\
\hline Antrum & (32) 2 & 6.2 & & (32) 4 & 12.5 & \\
\hline pilorum & (8) 0 & 0 & & (8) 0 & 0 & \\
\hline \multicolumn{7}{|l|}{ Tumor Type } \\
\hline Intestine & (90) 15 & 16.7 & 0.116 & (90) 14 & 15 & 0.572 \\
\hline Diffuse & (30) 1 & 3.3 & & (30) 6 & 20 & \\
\hline \multicolumn{7}{|c|}{ Tumor Differentiation } \\
\hline Well & (42) 3 & 7 & 0.343 & (42) 6 & 14 & 0.603 \\
\hline Moderate & (48) 8 & 16 & & (48) 10 & 20 & \\
\hline Poor & (30) 5 & 16 & & (30) 4 & 13 & \\
\hline \multicolumn{7}{|l|}{ Tumor T } \\
\hline T1 & (8) 4 & 50 & 0.011 & (8) 4 & 50 & 0.016 \\
\hline $\mathbf{T} 2$ & (22) 4 & 18 & & (22) 6 & 27.2 & \\
\hline T3 & (69) 6 & 8.7 & & (69) 8 & 11.5 & \\
\hline T4 & (21) 2 & 9.52 & & (21) 2 & 9.5 & \\
\hline \multicolumn{7}{|l|}{ Tumor $\mathbf{N}$} \\
\hline No & (26) 6 & 23 & 0.064 & (26) 8 & 30 & 0.115 \\
\hline N1 & (44) 7 & 15.9 & & (44) 6 & 13.6 & \\
\hline N2 & (41) 1 & 2.4 & & (41) 6 & 14.6 & \\
\hline N3 & (9) 2 & 22 & & (9) 0 & 0 & \\
\hline
\end{tabular}




\begin{tabular}{|c|c|c|c|c|c|c|}
\hline \multicolumn{7}{|c|}{ Tumor M } \\
\hline M0 & (112) 14 & 12.5 & 0.595 & (112) 20 & 17.5 & 0.349 \\
\hline M1 & (8) 2 & 25 & & (8) 0 & 0 & \\
\hline \multicolumn{7}{|c|}{ Tumor stage } \\
\hline I & (14) 4 & 28.5 & 0.024 & (14) 4 & 28.5 & 0.295 \\
\hline II & (52) 9 & 17.3 & & (52) 10 & 19.2 & \\
\hline III & (46) 1 & 2.17 & & (46) 6 & 13 & \\
\hline IV & (8) 2 & 25 & & (8) 0 & 0 & \\
\hline GC & 16 & 13.3 & & 20 & 16.6 & \\
\hline
\end{tabular}

\section{Discussion}

The current study aimed at determining the frequency of KRAS codon 12 and 13 point mutations in stomach cancer in Iranian population and comparing the results with general population. KRAS, an oncogene located on chromosome 12p12.1 plays a significant role in downstream signaling of EGFR pathway. Mutations in KRAS gene induce uncontrolled activation of RAS protein (3). Ras protein transforms sigp nals from EGFR to mitogen activated protein kinas (MAPKs). Ras protein is located in the inner region of cell membrane and controls cell growth proliferation and motility as well as metastasis and angiogenesis. The current study employed a PNA clamp-PCR based method.

By PNA clamp-PCR method, 16(13.3\%) KRAS codon 12 and 20(16.7\%) KRAS codon 13 point mutations were observed among the 120 stomach cancer samples. In the current study, $30 \%$ of all GCs showed KRAS codon 12 and 13 mutations; the current study data were similar to those of Polane et al., which reported $30.9 \%$ as frequency of KRAS mutations in patients with GC (9).

Grieken et al., in UK reported KRAS mutations in $4.2 \%$ of cases with GC (2). In a series of studies, the frequency of $K R A S$ gene mutations were $11.8 \%$, $21 \%$, and $11.4 \%$ in patients with GC (10), (11), (12), (13). In contrast to the current study results, Motsova et al., (2013) detected KRAS mutations in 1\% of similar patients. Some of the reasons for disagreements between the findings of the study by Motsova et al., and those of others attribute to sample sizes, different methodologies, and different analysis methods of the mentioned gene mutation.

Of the 120 studied gastric adenocarcinomas, 13\% had KRAS mutation codon 12 and $16 \%$ codon 13 (Table 1). This result was consistent with those of other recent studies of GC which revealed low incidence of KRAS mutations (7\%-20\%) (10). There was a significant correlation between $K R A S$ mutation codons and sites; $33 \%$ of $K R A S$ mutation codon 12 and $66 \%$ of codon 13 arose from gastric fundus $(P=0.015)$. Zhao et al., showed that all eight $K R A S$ mutant gastric tumors arose from gastric antrum $(P=0.002)(8)$, but three were from gastric body. Most of the current study $K R A S$ mutated cases were moderately differentiated tumors, while most of KRAS mutant cases reported by Zhao et al., were well differentiated tumors (14); 50\% of KRAS mutations codon 12 and 13 were T1 tumor $(P=0.011, P=0.016)$, but other studies did not report significant correlations between KRAS mutations and TNM stage (12). In the current study, the highest frequency of $K R A S$ mutations was observed in stage I (28.5\%), this result was similar to that of the recent study by Zhao et al. (21\%)(14). Almost all of the current study KRAS mutations were diffuse type, which was in contrast with those of other studies. It is mentioned that KRAS mutations are detectable in intestinal type and it is not a feature of diffuse type carcinoma (15).

\section{Conclusion}

In conclusion, the overall frequency of $K R A S$ codon 12 and 13 mutations in GC in the current study population was 30\%. Frequency of $K R A S$ codon 12 and 13 mutations showed significant correlation with tumors 
location. This information may be an important diagnostic tool for physicians managing patients with atrophic gastritis.

\section{Conflict of Interests}

Authors declared no conflict of interests.

\section{Reference}

1. Lee S-H, Ahn B-K, Baek S-U, Chang H-K. BRAF mutation in multiple primary cancer with colorectal cancer and stomach cancer. Gastroenterology report. 2013;1(1):70-4. https:// doi.org/10.1093/gastro/got004 PMID:24759670 PMCID:PMC3941443

2. Van Grieken N, Aoyma T, Chambers P, Bottomley D, Ward L, Inam I, et al. KRAS and BRAF mutations are rare and related to DNA mismatch repair deficiency in gastric cancer from the East and the West: results from a large international multicentre study. $\mathrm{Br} \mathrm{J}$ Cancer. 2013;108(7):1495-501. h https://doi. org/10.1038/bjc.2013.109 PMID:23511561 PMCID:PMC3629423

3. Kang JY, Park CK, Yeo CD, Lee HY, Rhee $\mathrm{CK}$, Kim SJ, et al. Comparison of PNA clamping and direct sequencing for detecting KRAS mutations in matched tumour tissue, cell block, pleural effusion and serum from patients with malignant pleural effusion. Respirology. 2015;20(1):138-46. https://doi.org/10.1111/ resp.12413 PMID:25302858

4. Malekzadeh R, Derakhshan MH, Malekzadeh Z. Gastric cancer in Iran: epidemiology and risk factors. Arch Iran Med. 2009;12(6):576-83. PMID: 19877751

5. Laur6n P. The two histological main types of gastric carcinoma: diffuse and so-called intestinal-type carcinoma. Acta Pathol Microbiol Scand. 1965;64:31-49. https://doi.org/10.1111/ apm.1965.64.1.31

6. Karapetis CS, Khambata-Ford S, Jonker DJ, O'Callaghan CJ, Tu D, Tebbutt NC, et al. Kras mutations and benefit from cetuximab in advanced colorectal cancer. N Engl J Med.
2008;359(17):1757-65. https://doi.org/10.1056/ NEJMoa0804385 PMID:18946061

7. Liu Z-M, Liu L-N, Li M, Zhang Q-P, Cheng S-H, $\mathrm{Lu}$ S. Mutation detection of KRAS by high-resolution melting analysis in Chinese with gastric cancer. Oncology reports. 2009;22(3):515-20. https://doi.org/10.3892/or_00000465

8. Corso G, Velho S, Paredes J, Pedrazzani C, Martins D, Milanezi F, et al. Oncogenic mutations in gastric cancer with microsatellite instability. Eur J Cancer. 2011;47(3):443-51. https://doi. org/10.1016/j.ejca.2010.09.008 PMID:20937558

9. Kelley JR, Duggan JM. Gastric cancer epidemiology and risk factors. J Clin Epidemiol. 2003;56(1):1-9. https://doi.org/10.1016/S08954356(02)00534-6

10. Okumura T, Ericksen RE, Takaishi S, Wang SS, Dubeykovskiy Z, Shibata W, et al. K-ras mutation targeted to gastric tissue progenitor cells results in chronic inflammation, an altered microenvironment, and progression to intraepithelial neoplasia. Cancer Res. 2010;70(21):8435-45. https://doi.org/10.1158/0008-5472.CAN-10-1506 PMID:20959488 PMCID:PMC2970750

11. Peng N, Zhao X. Comparison of K-ras mutations in lung, colorectal and gastric cancer. Oncol Lett. 2014;8(2):561-5. https:// doi.org/10.3892/ol.2014.2205 PMID: $\underline{25013470}$ PMCID:PMC4081128

12. Lee KH, Lee JS, Suh C, Kim SW, Kim SB, Lee $\mathrm{JH}$, et al. Clinicopathologic significance of the K-ras gene codon 12 point mutation in stomach cancer. An analysis of 140 cases. Cancer. 1995;75(12):2794-801. https://doi. org/10.1002/1097-0142(19950615)75:12<2794::AID-CNCR2820751203>3.0.CO;2-F

13. Washington K. 7th edition of the AJCC cancer staging manual: stomach. Ann Surg Oncol. 2010;17(12):3077-9. https://doi.org/10.1245/ $\underline{\text { s10434-010-1362-z }}$ PMID:20882416

14. Zhao W, Chan TL, Chu KM, Chan AS, Stratton MR, Yuen ST, et al. Mutations of BRAF 
and KRAS in gastric cancer and their association with microsatellite instability. Int J Cancer. 2004;108(1):167-9. https://doi.org/10.1002/ ijc.11553 PMID:14618633
15. Panani AD. Cytogenetic and molecular aspects of gastric cancer: clinical implications. Cancer Lett. 2008;266(2):99-115. https://doi.org/10.1016/j.canlet.2008.02.053 PMID: 18381231

\section{How to Cite This Article}

Ayatollahi H, Tavassoli A, Jafarian AH, Alavi A, Shakeri S, Shams F, Sheikhi M, Motamedi Rad N, Sadeghian MH, Bahrami A. KRAS Codon 12 and 13 Mutations in Gastric Cancer in the Northeast Iran. Iranian Journal of Pathology, 2018; 13(2): 167-172. 